
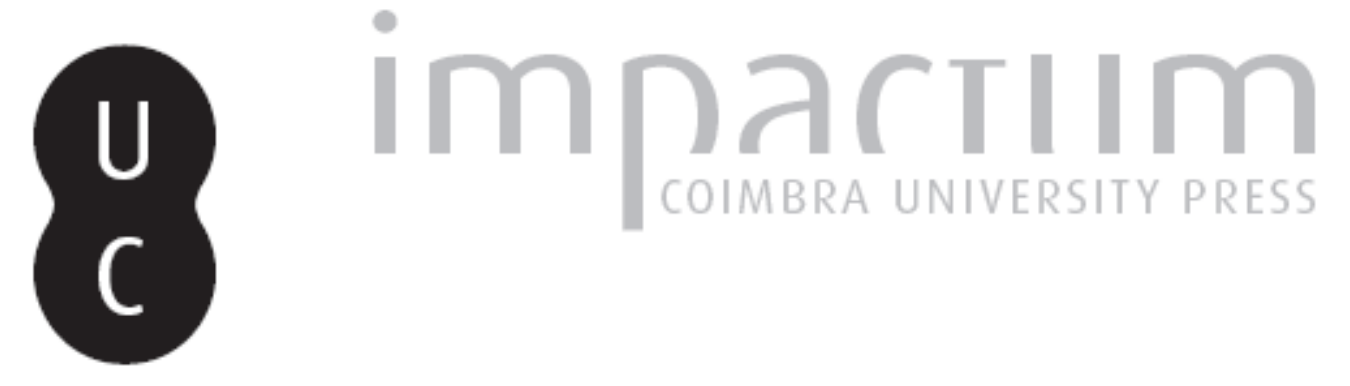

\title{
Ficção e poder na Eneida de Virgílio
}

\section{Autor(es): $\quad$ Teixeira, Cláudia Afonso}

Publicado por: Centro de História da Universidade de Lisboa

URL persistente:

URI:http://hdl.handle.net/10316.2/23786

DOI:

DOI:http://dx.doi.org/10.14195/0871-9527_19_9

Accessed : $\quad$ 26-Apr-2023 16:10:53

A navegação consulta e descarregamento dos títulos inseridos nas Bibliotecas Digitais UC Digitalis, UC Pombalina e UC Impactum, pressupõem a aceitação plena e sem reservas dos Termos e Condições de Uso destas Bibliotecas Digitais, disponíveis em https://digitalis.uc.pt/pt-pt/termos.

Conforme exposto nos referidos Termos e Condições de Uso, o descarregamento de títulos de acesso restrito requer uma licença válida de autorização devendo o utilizador aceder ao(s) documento(s) a partir de um endereço de IP da instituição detentora da supramencionada licença.

Ao utilizador é apenas permitido o descarregamento para uso pessoal, pelo que o emprego do(s) título(s) descarregado(s) para outro fim, designadamente comercial, carece de autorização do respetivo autor ou editor da obra.

Na medida em que todas as obras da UC Digitalis se encontram protegidas pelo Código do Direito de Autor e Direitos Conexos e demais legislação aplicável, toda a cópia, parcial ou total, deste documento, nos casos em que é legalmente admitida, deverá conter ou fazer-se acompanhar por este aviso.

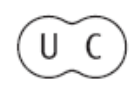



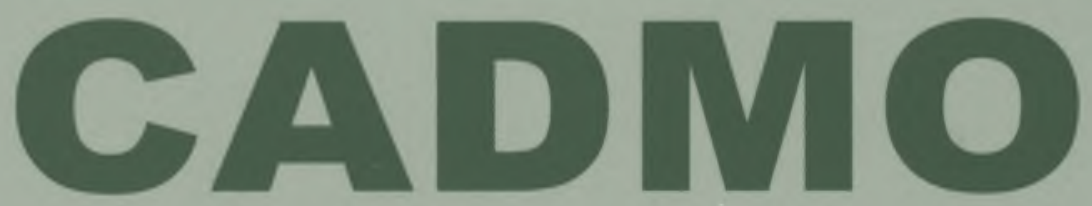

Revista de História Antiga

\author{
Centro de História \\ da Universidade de Lisboa
}

19

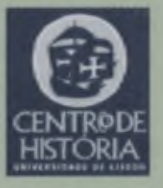

430 =

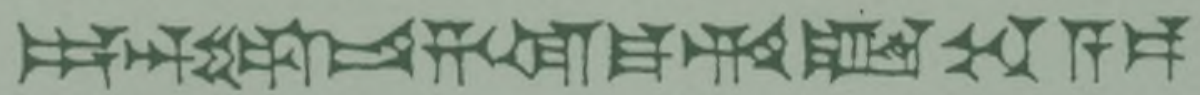

MHNIN AEI $\Delta$ E $\Theta E A ~ \Pi H \Lambda H I A \triangle E \Omega$ 


\title{
FICÇÃO E PODER NA ENEIDA DE VIRGÍLIO
}

\author{
CLÁUDIA AFONSO TEIXEIRA \\ Universidade de Évora \\ caat@uevora.pt
}

\section{Resumo}

A épica de Virgílio constitui uma das muitas obras nas quais é visível a relação da literatura com o poder. Essa ligação, visível desde logo no processo de formação do herói e na progressiva consciencialização de que a missão de que se encontra investido implica um acréscimo de capital simbólico relativamente ao passado troiano, ganha uma evidente expressividade no final do livro VI, no momento em que Anquises enuncia os valores e as normas de regência do império. No entanto, apesar da evidente ligação à época de Augusto e à política imperial, a narrativa não deixa de apresentar fracturas ideológicas, que contrastam com os elementos da "matriz política" subjacente à Eneida, bem como episódios que parecem constituir-se como alternativa ao modelo apresentado por Anquises no livro VI. Neste sentido, o objectivo deste texto, que se centrará especialmente na análise de episódios dos livros VI, VIII e XII, será o de cotejar os elementos discursivos de natureza apologética presentes na narrativa com os elementos que derrogam essa apologia e, desta forma, apresentar conclusões relativamente à relação da épica virgiliana com a matriz política que Ihe está associada.

Palavras-chave: Épica latina; Virgílio; Século I; Roma; Augusto.

\section{Abstract}

The Virgilian Epic constitutes one of the many works in which the relation between Literature and power is visible. This connection is immediately 
spotted in the hero's formation process and in his gradual awareness that his mission implies an addition of symbolic capital to the Trojan past gains an unmistakable expressiveness at the end of book VI, the moment where Anchises enunciates the values and the norms of the Empire's ruling. However, in spite of the evident linking to the time of Augustus and the imperial politics, the narrative presents ideological fractures, which contrast with the elements of the "political matrix" inherent to Aeneid, as well as episodes that seem to appear as an alternative to the model presented by Anchises in book VI. In this sense, the purpose of this paper - that will be centred especially in the analysis of episodes of books VI, VIII and XI - will be to speck the discursive elements of an apologetical nature present in the narrative with elements that retract this apology and, in such a way, to draw conclusions concerning the relation of the Virgilian Epic with the political matrix that is associated to it.

Key-Words: Latin Epic; Vergil; $1^{\text {st }}$ Century; Rome; Augustus.

Considerada como um texto que, em perspectiva simbólica, evoca sempre, de forma explícita ou implícita, as linhas definidoras de um povo, de uma nação, de um programa ideológico, a épica aparece aos olhos do leitor como um texto de coesão, representativo de um dado momento da história, factual ou mitológico, consubstanciador dos elementos e valores considerados centrais para o povo que representa. Exemplo desta evocação, no panorama das literaturas ocidentais, constitui a Eneida, vista, ao longo dos tempos, como o modelo literário da definição dos valores romanos, em estreita associação ao tempo do magistério de Augusto: «il [...] poema, dedicato a Augusto, è un'epica nazionale che contempera la tradizione del racconto eroico e l'esigenza di una narrazione storico-celebrativa dove il mito dell'età dell'oro rinnovata e le profezie della grandezza di Roma si intrecciano a forgiare l'identità e i destini di un populo "(1). Neste sentido, se a estreita associação da Eneida de Virgílio ao plano da história facilita a detecção de elementos de natureza política e ideológica, que, ora em quadro referencial implícito, ora em quadro referencial explícito, vão surgindo na narrativa, o mesmo se não pode dizer das interpretações a dar ao significado do seu conjunto.

Com efeito, mais do que pautada por variações pontuais, a interpretação da Eneida, vive ainda hoje do movimento de adesão por parte dos especialistas às considerações estruturantes de duas escolas - as denominadas "escola europeia" e "escola "pessimista" de Harvard» -, 
cujas interpretações do poema virgiliano dão corpo a duas alegorias políticas radicalmente opostas.

A primeira, partindo da comparação com o mundo homérico, centra no texto a visão do devir histórico e da construção positiva do império. Apoiada no conceito de um heroísmo, que no brilho individual e na força de heróis como Eneias vê a subordinação aos ditames da construção de uma nova visão civilizacional, a Eneida é interpretada como a celebração de um momento histórico, que se perspectiva como o expoente máximo de uma caminhada para uma ordem, a qual assenta os seus pressupostos em novos conceitos, em novos valores e em novos objectivos, ou seja, nos fundamentos éticos, morais e políticos da sociedade romana; a segunda posição realça a fragilidade da visão anterior ao evidenciar as contradições da história que Virgílio nos conta no tocante à instituição dessa nova ordem. Apoiada no eco do existencialismo pessimista da actualidade, que lança sobre os grandes discursos utópicos da ordenação do mundo um olhar de suspeição, esta escola vê a Eneida como veículo seguro da demonstração de que a natureza humana se constitui, por si só, como um elemento destrutivo da utopia e da ordem. Esta desconfiança latente, amplamente salientada no texto virgiliano, que, entre outros factores, se evidencia na constatação de que o herói, símbolo da construção dessa nova ordem política, acaba afinal por sucumbir aos erros relativamente aos quais deveria ser símbolo de debelação, retira qualquer possibilidade de identificação do mundo simbólico do poema com a ideia de exaltação e celebração do império que tradicionalmente se associa à Eneida.

A oposição entre as duas orientações, mais do que ostentações filosóficas de natureza interpretativa, reflecte bem e de forma precisa as dificuldades que o texto apresenta; dificuldades que resultam sobretudo da leitura da segunda parte da Eneida, onde o quadro do estabelecimento no Lácio oferece os suportes ficcionais adequados a uma correlação imediata com a matriz histórica e política do império.

História e ficção formam uma bilateralidade conceptual, em que, se ao plano da história vai caber o estatuto de paradigma, ao plano da narrativa cabe o de exemplificação desse paradigma. Esta relação conceptual desenvolve-se em três momentos determinantes que, no seu conjunto, vão formar a estrutura coesa dos pressupostos políticos e ideológicos, extensíveis quer ao plano da história, quer ao plano da narrativa; e é do jogo que se estabelece entre estes dois eixos que, por sua vez, as ilações no tocante à própria natureza ideológica da Eneida resultam, simultaneamente, mais profícuas e mais difíceis. 
O primeiro e talvez maior, ou pelo menos mais conhecido, indicador ideológico da Eneida é transmitido no livro VI, no momento em que Anquises, tomando por base a teoria da transmigração, enumera o catálogo dos heróis romanos e revela o futuro glorioso de Roma.

Esse indicador, longe de constituir uma aquisição adâmica, assenta em uma reformulação de um princípio que, desde os primeiros momentos, se assumiu como um dos elementos definidores da narrativa e que se exprime nas ideias de restabelecimento do povo troiano, e de refundação civilizacional; mas esta refundação que, até ao momento, se encontrava eminentemente associada à noção de restabelecimento imediato, isento de outros objectivos para além do da continuidade do paradigma troiano, beneficia agora de um reenquadramento valorativo, que se traduz na subordinação dessa refundação aos ditames de uma nova ideia de estado, que tem nas normas enunciadas por Anquises, em 6.851-853(2), não só o modelo rígido da sua orientação da moral, como a consubstanciação da alegoria política, sancionada pela celebração do novo código augustano: “(....) Imponere présente morem comme un surplus qui s'ajoute à l'état de paix et lui donne forme et sens. La paix romaine n'est pas seulement l'absence de la guerre, elle sera aussi ordre, légalité, langage commun, civilisation. (....)»(3). Este reenquadramento determina, por sua vez, que a noção de sentido do dever, um dos traços definidores do herói desde as primeiras linhas do poema, acompanhe esta evolução qualitativa: amor patriae e sentido do dever passam agora a consubstanciar-se, não como meros indicadores formais da natureza do herói, mas como os elementos agilizadores dos pressupostos ético-morais de uma conduta política que se vê obrigada a uma total subordinação a um sentido de estado.

Estes elementos, que adquiriram, no canto $\mathrm{VI}$, uma formulação normativa precisa, vão ser alvo de uma contextualização no livro VIII, que vai não só estreitar a relação entre história e ficção, como explanar o sentido da aplicação desses pressupostos ao plano imediato da narrativa. Essa expansão qualitativa resulta das duas grandes alegorias civilizacionais presentes nas narrativas de Hércules e Caco e de Saturno. Na primeira, Hércules persegue e mata o monstro semi-humano, filho do deus Vulcano, símbolo de uma barbárie primitiva e anti-social. Após a derrota de $\mathrm{Caco}$, o caos primitivo dá lugar a uma ordem de natureza humana. Na outra narrativa, conta-se a acção Saturno ${ }^{(4)}$, o deus civilizador e unificador (8.321-22) das gentes bárbaras da região, uma raça de homens "que não tinham nem tradição, nem cultura" 
(8.316) e aos quais o deus concedeu as primeiras leis (8.322) e conduziu ao estado de paz da Idade do Ouro (8.324-25).

$\mathrm{Se}$, no tocante à analogia com o plano histórico, as relações entre as res gestae de Augusto e Hércules, suscitadas pela narrativa foram, circunstanciadamente, apontadas pela crítica, pois a história «is treated with an evident and purposeful consciousness of an analogy between Hercules and the younger Caesar, Octavian, victor of Actium and restorer of peace to the Roman world. Both are performers of prodigious feats, both are benefactors of mankind, liberating the world from terrors and oppressors and making it possible for life to be lived in peace» ${ }^{(5)}$; já, na narrativa de Saturno a evocação amplifica exponencialmente essa relação, através das referências ao princípio da união dos povos e da actividade legislativa como motores do acto de civilização(6). Neste sentido, se a oposição entre civilização e barbárie estabelece uma correspondência estreita com o universo histórico da obra, também o plano ficcional da narrativa se revê nesta oposição valorativa: uma oposição que, simultaneamente, vai justificar e determinar, de um ponto de vista ideológico, a superioridade de uma das partes em conflito sobre a outra.

No final do livro VIII, a ekphrasis do escudo de Eneias completa o modelo, através da articulação da guerra civil com a desordem de natureza social e política, que pode pôr em causa uma sociedade já organizada, promovida por aqueles, que, pela sua actividade subversiva, tentam, como Catilina, destruir Roma, ou que, como Marco António, aliado a um reino estrangeiro, põem em causa a harmonia de Roma. Só a vitória de Augusto promove definitivamente o fim da desunião e o estabelecimento de uma nova era: a da pax romana(7). E, neste sentido, o plano bélico ficcional adquire agora a sua formulação definitiva. Se a superioridade do ideal troiano, evocada pela primeira narrativa de Evandro, identificara o elemento bélico como um meio de conseguir a civilização, adiciona-se agora a noção de que a guerra, distante dos pressupostos do antigo código, pode constituir-se como o único meio de garantia do equilíbrio temporal e do triunfo histórico da civilização e da pax, que lhe está intrinsecamente associada, sobre a desordem.

Os pressupostos ideológicos decorrentes dos episódios citados - subordinação do dever à moral de estado, debelação da barbárie em prol da criação da civilização, e reenquadramento valorativo da guerra como garantia da recondução dos povos à harmonia social -, encontram um meio de expressão privilegiada no plano bélico que, nesta altura, domina o poema. Com efeito, o quadro valorativo que 
deles resulta pressupõe-se orientador da trajectória individual do herói e da própria saga troiana, ou, como observa Boyle, "his series of forceful moral imperatives, which brings to a climax the vision of Rome's future majesty and greatness (...) constitutes both the first and the only fully overt declaration to Aeneas of the raison d'être of his mission» ${ }^{(8)}$.

No entanto, é precisamente o facto de esses pressupostos não constituírem um conjunto de afirmações isoladas da narrativa ficcional que levanta o primeiro problema relativo à coesão da Eneida.

Ao longo dos quatro últimos livros, Virgílio lança, na obra, indícios muito claros relativamente aos motivos que justificam a vitória troiana sobre a confederação itálica. Esses motivos inscrevem-se no contraste civilizacional, ou seja, na diferença entre os modelos de civilização representados por cada uma das partes em confronto. A definição desses modelos é sugerida, entre outros, pelos comportamentos das duas personagens maiores - Eneias e Turno. A recorrência da submissão de Turno à ira e ao furor, a atitude antitética dos dois heróis nos combates com Lauso ${ }^{(9)}$ e Palante, o bom acolhimento de Eneias à possibilidade de um tratado de paz, quando se encontra em manifesta vantagem, constituem-se não só como elementos definidores da pietas e a humanitas do herói, mas indiciam também a sua aplicação ao nível da visão de uma sociedade, capaz, de acordo com o princípio da pax romana, de aglutinar os opositores no sentido da nação.

Deste modo, e embora Eneias cometa erros atentatórios da humanitas, quando, nos combates, cede por vezes à fúria e à ira ${ }^{(10)}$, os motivos enunciados parecem suficientes para a demonstração máxima dos factores que justificam a sorte política, quer de Eneias, quer de Turno, enquanto representação da superioridade da humanitas sobre a fúria e do combate imbuído de princípios morais sobre o combate que parece conter a sua finalidade no próprio combate - em suma: do primado da civilização e da ordem sobre a desordem.

No entanto, se, politicamente, a derrota de Turno representa, à luz do devir histórico, a queda do modelo anacrónico de sociedade em benefício do modelo ideal de civilização representado pelos Troianos, já a sua morte, após uma comovente súplica em que se declara uictus, que evoca o princípio de Anquises de parcere subiectis, aliado ao facto de a dinâmica comportamental e discursiva de Eneias assentar não em questões de ordem política e social(11), mas apenas no princípio da amicitia que o liga a Palante, deixa, sem solução o episódio final. 
E, neste sentido, fazemos eco das interrogações de Jonhson: "If Aeneas is not only symbolic of classical rational freedom, but he is also himself, in his muthos, possessed of rational freedom, why do we last view him as a victim of the very anger and madness that he has so gallantly opposed throughout the poem? Has the champion of the Western civilization triumphed? Over his foes, yes; over the immediate evils that Juno has designed, yes. But over what Juno is and wants and stands for? I think the general design and in particular the closure of the poem argue against Aeneas' - victory over those evils.»(12)

$\mathrm{E}$, de facto, o poema deixara indícios de que o desfecho poderia ser este. A estrutura aparentemente coesa do discurso político-ideológico não deixou de apresentar fracturas ao longo dos últimos livros que, se não prepararam este final, têm pelo menos de ser consideradas para a sua interpretação. A primeira fractura é observável logo no canto VI, no qual a alusão à morte de Marcelo $^{(13)}$, no quadro de uma alegoria política de valor indiscutivelmente optimista, deixa antever o equilíbrio precário da consecução ideológica de um ideal histórico em um plano humano. A contingência e a fatalidade constituem-se, assim, como factores de interferência que culminam senão na tragédia da história, pelo menos na mitigação do ideal ${ }^{(14)}$ que Ihe está associado. E de igual forma, embora não constitua uma verdadeira fractura, também, no canto VIII, as tonalidades exemplares da ordem baseada na simplicitas e na paupertas, que Virgílio imprime à região da futura Roma, uma ordem muito diferente da ordem política e grandiosa profetizada por Anquises, parecem, apesar de reflexo do imaginário mais remoto e menos visível da obra, configuar uma alternativa poderosa à ideia de império. E para a noção de que o poema acaba com um sabor a cinzas e morte não são igualmente despiciendos a maldição que Dido pôs sobre Roma, nem a ironia particular que Júpiter, no livro $X$ $(10.11-14)^{(15)}$, coloca na referência às guerras púnicas.

Desta forma, caso se considere que o desfecho constitui uma estrutura de síntese de toda a evolução da obra, o último acto de Eneias põe novamente em primeira linha o problema de uma visão que, nas palavras de Putnam, "demeans both father and son, and darkens the Roman future, at least as Virgil envisions it»(16).

No entanto, mais do que traduzir uma ideia anti-augustana e crítica dos pressupostos ideológicos sobre os quais assenta a ideia de uma Roma aeterna, a última acção de Eneias parece dar continuidade valorativa aos elementos que já tinham indiciado a extensa contradição expressa pela obra: se, como demonstrado no caso de Marcelo, a 
contingência e a fatalidade impedem a consecução plena da história, agora são as fragilidades intrínsecas ao plano humano, existencialmente considerado, que emergem como factor determinante desse impedimento. E tal pressuposto explicita, em última análise, a ideia de que o modelo de construção positiva, indiscutivelmente associado à Eneida de Virgílio, não deixa de ter a capacidade - e nisto talvez resida a sua maior virtude - de integrar os elementos da natureza humana que determinam que o equilíbrio entre o ideal e o realizável seja sempre precário.

\section{Notas}

(1) S. ZATTI, II modo epico, Roma/Bari, 2000, 40-41.

(2) 6.851-853: "Tu regere imperio populos, Romane, memento / (hae tibi erunt artes), pacique imponere morem,/ parcere subiectis et debellare superbos". («"A ti, Romano, lembra-te, compete reger os povos sob o teu império (estas serão as tuas artes), impor as regras da paz, poupar os submetidos e debelar os arrogantes"»).

(3) J. PERRET, Virgile. Énéide I-III, Paris, 19771980 (ed. Belles Lettres, texto base das citações), 75.

(4) 8.314-336: "Haec nemora indigenae Fauni Nymphaeque tenebant / gensque uirum truncis et duro robore nata,/ quis neque mos neque cultus erat nec iungere tauros / aut componere opes norant aut parcere parto,/sed rami atque asper uictu uenatus alebat./ Primus ab aetherio uenit Saturnus Olympo / arma louis fugiens et regnis exsul ademptis./ Is genus indocile ac dispersum montibus altis / composuit legesque dedit Latiumque uocari / maluit, his quoniam latuisset tutus in oris./ Aurea quae perhibent, illo sub rege fuere / saecula: sic placida populos in pace regebat, / deterior donec paulatim ac decolor aetas / et belli rabies et amor successit habendi". "Estes bosques tinham por habitantes os Faunos e as Ninfas indígenas e uma raça de homens nascida dos troncos do duro carvaIho, que não tinham nem tradição, nem cultura, nem conheciam a maneira de atrelar os touros, de armazenar os bens ou de poupar as suas provisões: os ramos e uma penosa caça Ihes forneciam alimentos com que viver. O primeiro que veio do Olimpo etéreo, fugindo às armas de Júpiter, foi Saturno, exilado e desapossado do seu reino. Foi ele quem reuniu este povo indócil e disperso pelas altas montanhas, Ihes deu leis e quis que [esta região] se chamasse Lácio, por ter encontrado nestas paragens latíbulo seguro. A idade, a que chamam Áurea, decorreu sob o seu reinado. Em tão plácida paz governava os seus povos, até que, aos poucos, Ihe sucedeu uma idade inferior e degradada e a fúria da guerra e a cupidez da posse.m

(5) W. A. CAMPS, An introduction to Virgil's Aeneid, Oxford, 1969, 98-99.

(6) A relação com a narrativa ficcional, é enfatizada logo a seguir, em 8.288-293, no rememorar dos trabalhos do herói, cujos exempla articulam uma relação de sentido que sublinha a vitória sobre Juno e o caos.

(7) A. D. BOTHA, "Aspects of prophecy in Virgil's Aeneid", Akroterion 37, 1992, 14, observa, no entanto, que "The ecphrasis too, delimits Augustus' prowess as the outcome of a historical design initiated by heaven. Not only is the battle of Actium portrayed as a 
theomachy but the goods also foster the collective elements, Italian and Roman, which invest Augustus' victory. His triumph is thereby reduced to the fulfillment of a common destiny acting on a broad basis of human endeavor."

(8) A. J. BOYLE, The chaonian dove. Studies in the Eclogues, Georgics, and Aeneid of Virgil, Leiden, 1986, 136.

(9) Relativamente ao contraste entre a atitude de Eneias, nessa altura, e a decisão de dar morte a Turno, vide M. PUTNAM, "Pius Aeneas and the metamorphosis of Lausus", Arethusa 14, 1981, 139155.

(10) Eneias é considerado saeuus (10. 569), iratus (12.946), e furens (10.545). Também Ascânio e Palante são considerados audaces (respectivamente em 9.625 e 8.110).

(11) Parece significativo também o facto de Eneias não assentar a decisão de dar morte ao inimigo no argumento religioso e moral que, com propriedade, poderia invocar, ou seja, no facto de Turno não ter oferecido as armas de Palante à divindade (o que constituía uma manifestação de hybris). Este factor parece, assim, acentuar a ideia de que a morte de Turno resulta de uma decisão pessoal, tomada por Eneias.

(12) W. R. JOHNSON, Darkness visible. A study of Vergil's Aeneid, Berkeley, Los Angeles, London, 1976, 13.

(13) B. OTIS, Virgil. A study in civilized poetry, Oxford, 1964, 303, observa: "Marcellus thus prefigures the similar heroes of the last six books: Pallas, Lausus, Euryalus, Camilla. The ordeal of empire is based on sacrifice, especially sacrifice of the young. Otherwise, the destructive influence of hybris, inhuman pride, could not have been avoid."

(14) F. SOLMSEN, "The world of the dead in book 6 of the Aeneid", in E. L. Harrison ed., Oxford readings in Vergil's Aeneid, Oxford, 1990, 222-223, observa que "In the Aeneid, Virgil is the poet of Rome's greatness (....) but he is more than this. He also is the poet whose feelings respond with a warmth unknown before his days to the sorrows and struggles of individuals, who would wonder whether such trials were all that the divine world order had allotted to man, and who would be receptive to the Platonic and Stoic teachings about release from the world and the return of soul to its sublime origin. Even in his national epic, his sympathy with the individual in his physical or emotional sufferings manifests itself everywhere. (....) In the presentation of Rome's glorious future the perspective from beyond is maintained."

(15) 10.11-14: Adueniet iustum pugnae (ne arcessite) tempus, / cum fera Karthago Romanis arcibus olim / exitium magnum atque Alpis immittet apertas: / tum certare odiis, tum res rapuisse licebit. "Chegará o momento certo para a peleja (não o apresseis), quando um dia a feroz Cartago lançar nas colinas romanas um grande flagelo, uma vez transpostos os Alpes: então podereis pelejar com ódio, então podereis saquear.m

(16) M. PUTNAM, "Virgil's Inferno", MD 18, 1987, 193; idem, The poetry of the Aeneid. Four studies in imaginative unity and design, Cambridge/Massachusetts, 1966, 200-201, transporta as consequências desta interpretação para o próprio universo da construção da épica: "When the epic opened it was Aeneas' turn to shudder with cold as the winds, the first pawns of Juno's anger, threatened imminent death (soluuntur frigore membra: 1.92). Now, as the poem reaches the climax, it is one of Virgil's most bitter and cogent ironies that he uses this very phrase at the exact moment Aeneas becomes the personification of avenging wrath and brings death to Turnus. The wheel has come full circle. It should cause little wonder when Juno seems to surrender so readily to Jupiter's plea that she give over her anger in contemplation of future Roman magnificence. For, according to the poet whishes, it is she, not Aeneas, nor the grandeur for which Augustus seems to stand, who 
wins the greatest victory as the soul of Turnus passes with a resentful moan to the shades below.»; J. R. WILSON, "Action and emotion in Aeneas", G\&R 16, 1969, 74-75, contesta a ideia ao afirmar que "To my own mind, a conscious anti-Augustanism in Virgil (....) is quite unacceptable. The systematic blackening of Turnus' character in itself goes against such a view. And yet, in spite of Virgil's efforts, Turnus survives his moral blackening and the foul forces of death to emerge as an authentic hero while Aeneas, by his very good intentions, is ultimately an ineffectual sentimentalist who in the name of humanitas ravages the pristine Italian world just as he had ravaged the budding city of Carthage." 